\title{
HAK ASASI MANUSIA DALAM AL-KULLIYAT AL-KHAMS (PERSPEKTIF PEMIKIRAN ABDURRAHMAN WAHID)
}

\author{
Marya Alvina Alisha \\ maryaalisha18@gmail.com \\ Universitas Islam Negeri Sunan Ampel Surabaya \\ Majidatun Ahmala \\ mazida23@gmail.com \\ STAI Taruna Surabaya.
}

\begin{abstract}
Human Rights are one of basic rights that had by every human being who has become their destiny when they were born. Actually the Human Rights are not state's gifts, law or other human beings. Every humans need human rights to protect their dignity, as well as a moral foundation in associating and dealing each other. In Islam, human rights have a high priority by prioritizing collective rights rather than individual rights. Islam also teaches his people to respect each other and recognize the rights of one's life, because live and death are the power of Allah Almighty. Human Rights in Islam are written in Al-Kulliyat Al-Khams, namely hifzh al-din (protection against religion), hifzh al-nafs (protection of the soul), hifzh al-aql (protection of reason), hifzh al-nasl (protection of offspring), and hifzh al-maal (protection of property). Abdurrahman Wahid of familiarly known as Gus Dur is a person who has extremly respect about the human values which contained in Al-Kulliyat Al-Khams and shows a high commitment to realize of respect for human rights. Therefore, it is very interesting to know Human Rights in Al-Kulliyat Al-Khams, Abdurrahman Wahid's perspective to find out how his thoughts in realizing to bring into reality the protection of basic human rights.
\end{abstract}

Keyword: Human Rights, Al-Kulliyat Al-Khams, Abdurrahman Wahid

\section{Pendahuluan}

Hak-hak Asasi Manusia dalam Islam, dewasa ini telah menjadi wacana yang berkembang dan sumbernya berasal dari kehidupan Barat. Diskursus tentang hal tersebut belum selesai diperdebatkan. Di satu pihak berpendapat bahwa HAM hendaknya dilaksanakan secara seragam dan menyeluruh di seluruh penjuru dunia. Di lain pihak menghendaki penegakan HAM dan konsepsinya dari sudut pandang yang lebih spesifik dan sesuai dengan kondisi budaya dan keyakinan masyarakat setempat. 
Sejarah mencatat bahwa Abdurrahman wahid atau yang biasa dikenal dengan Gus Dur adalah sosok tokoh dengan berbagai potensi, kecerdasan, kemampuan dan penguasaan dalam berbagai bidang, yaitu bidang keagamaan, kesenian, budaya, sosial, politik, ekonomi, termasuk spiritualitas dan tasawuf. Banyak orang yang kesulitan dalam memahami berbagai tindakan dan kiprah Gus Dur, yang dalam banyak hal sering kali sulit diterima dengan nalar sederhana. Disamping ia termasuk bagian dari nasab yang bergaris putih dan biru, yaitu keturunan priyai dan kiai, tetapi juga disebabkan oleh kapasitas dan kompetensi keilmuan yang luar biasa dan kaya. ${ }^{1}$

Di kalangan pemuda NU pembaru, popularitas Gus Dur terutama didukung oleh cara-caranya yang demokratis dan merakyat dan ini sangat berbeda dengan tata cara dunia pesantren, meskipun begitu, Gus Dur juga tetap menunjukkan hormatnya kepada dunia ulama. Di lingkungan pesantren, pada awal 1990-an Abdurrahman Wahid merupakan sosok kebanggaan sebagai seorang pemimpin NU yang mempunyai peran nasional, tenar di kalangan internasional, dan terutama dapat menjadi tokoh penting dalam membela keadilan sosial. ${ }^{2}$ Hal menunjukkan tingginya nilai-nilai kemanusiaan yang diangkat dan dibela oleh Gus Dur.

Gus Dur memiliki hak-hak dasar manusia yang kapanpun dan dimanapun baik melalui tulisan-tulisannya, ceramah-ceramahnya maupun dalam sikap hidupnya, yang sering paling tidak menyebut lima dasar manusia yang harus dilindungi dan diselamatkan. Hak-hak dasar perlindungan tersebut diadopsi Gus Dur dari teori Ushul Fiqh (Dasar-dasar Hukum) yang ditemukannya dalam kitab klasik pesantren. Nama populernya Al-Kulliyat al-Khams (Lima Prinsip Kemanusiaan Universal). ${ }^{3}$

Oleh sebab itu, mengetahui pemikiran Abdurrahman Wahid atau Gud Dur tentang Hak Asasi Manusia dalam Al-Kulliyat al-Khams menjadi hal yang sangat menarik untuk digali lebih dalam melalui perjuangan-perjuangannya dalam merealisasikan al-Kulliyat al-Khams.

\footnotetext{
${ }^{1}$ Abdul Wahid, Karena Kau Manusia, Sayangi Manusia (Yogyakarta: Diva Press, 2018), 14.

${ }^{2}$ Andree Deillerd, Islam et Amee Dans L'Indonesie Contemporaine Les Pionniers de La Tradition, ed. Terj. Lesmana (Yogyakarta: LKiS, 1999), 409.

${ }^{3}$ Husein Muhammad, Sang Zahid: Mengarungi Sufisme Gud Dur (Yogyakarta: LKiS, 2012), 5. 


\section{Hak Asasi Manusia (Ham) Barat Dan Islam}

Menurut istilah, hak asasi manusia terbentuk dari tiga suku kata yaitu hak, asasi, dan manusia. Dua kata yang pertama, hak dan asasi merupakan kata yang berasal dari bahasa Arab. Sedangkan manusia berasal dari bahasa Indonesia. Hak dari kata haqq yang berarti kewenangan atau kewajiban untuk melakukan atau tidak melakukan sesuatu itu. Sementara asasi dari kata asasiy yang berarti bersifat dasar atau pokok. Dengan demikian dalam Bahasa Indonesia, HAM diartikan sebagai hak mendasar pada diri manusia. ${ }^{4}$

Menurut UU Nomor 39 Tahun 1999, Hak Asasi Manusia merupakan seperangkat hak yang melekat pada hakikat keberadaan manusia sebagai makhluk Tuhan Yang Maha Esa dan merupakan anugerah-Nya yang wajib dihormati, dijunjung tinggi dan dilindungi negara, hukum, pemerintah dan setiap orang demi kehormatan serta perlindungan harkat dan martabat manusia. ${ }^{5}$

Adapun ciri-ciri HAM, pertama, HAM tidak perlu diberikan, dibeli atau diwarisi, karena hak asasi termasuk sesuatu yang memang patut untuk dimiliki oleh manusia. Kedua, berlakunya hak asasi kepada semua orang tanpa memandang jenis kelamin, ras, agama, etnisitas, pandangan politik atau asal usul sosial, bangsa. Ketiga, larangan untuk melanggar HAM karena siapapun tidak mempunyai hak untuk membatasi atau melanggar hak orang lain. ${ }^{6}$

Terdapat perbedaan mendasar antara konsep HAM dalam Islam dan HAM dalam konsep Barat sebagaimana yang diterima oleh perangkat-perangkat Internasional. HAM dalam Islam didasarkan pada premis bahwa aktivitas manusia sebagai khalifah Allah di muka bumi. Sedangkan dunia barat, bagaimanapun percaya bahwa pola tingkah laku hanya ditentukan oleh hukumhukum Negara atau sejumlah otoritas yang mencukupi untuk tercapainya aturanaturan publik yang aman dan perdamaian semesta. ${ }^{7}$

\footnotetext{
${ }^{4}$ Sirajuddin dan Winardi, Dasar-Dasar Hukum Tata Negara Indonesia (Malang: Setara Press, 2015), 227.

5 Majda El Muhtaj, Hak Asasi Manusia Dalam Konstitusi Indonesia Dari UUD 1945 Sampai Dengan Perubahan UUD 1945 Tahun 2002 (Jakarta: Kencana Prenada Media Group, 2005), 116.

${ }^{6}$ Winardi, Dasar-Dasar Hukum Tata Negara Indonesia, 228.

${ }^{7}$ M.I.Patwari, Human Rights in Islamic Law, ed. Tahir Mahmood (New Delhi: Jaia Nagar, 1993), 62.
} 
Ahmad Kosasih membandingkan HAM dalam Universal Declaration of Human Rights (UDHR) dan HAM dalam Islam sebagai berikut: ${ }^{8}$

\begin{tabular}{|l|l|}
\hline \multicolumn{1}{|c|}{ HAM dalam UDHR } & \multicolumn{1}{|c|}{ HAM dalam Islam } \\
\hline $\begin{array}{l}\text { Bersumber pada pemikiran filosofis } \\
\text { semata }\end{array}$ & $\begin{array}{l}\text { Bersumber pada ajaran Al-Qur'an dan } \\
\text { Sunnah Nabi Muhammad SAW }\end{array}$ \\
\hline $\begin{array}{l}\text { Bersifat Antrofosentris (manusia } \\
\text { merupakan ukuran terhadap gejala } \\
\text { sesuatu) }\end{array}$ & $\begin{array}{l}\text { Bersifat theosentris (Tuhan Yang Maha } \\
\text { Tinggi dan manusia hanya mengabdi } \\
\text { kepada-Nya) }\end{array}$ \\
\hline $\begin{array}{l}\text { Lebih mementingkan hak daripada } \\
\text { kewajiban }\end{array}$ & $\begin{array}{l}\text { Keseimbangan antara hak dan } \\
\text { kewajiban }\end{array}$ \\
\hline $\begin{array}{l}\text { Lebih bersifat individualistik } \\
\text { Kepentingan sosial (kebersamaan) } \\
\text { diperhatikan. }\end{array}$ \\
\hline $\begin{array}{l}\text { Manusia dilihat sebagai pemilik } \\
\text { sepenuhnya hak-hak dasar. }\end{array}$ & $\begin{array}{l}\text { Manusia dilihat sebagai makhluk yang } \\
\text { dititipi hak-hak dasar Tuhan, dan oleh } \\
\text { karena itu mereka wajib mensyukuri } \\
\text { dan memeliharanya }\end{array}$ \\
\hline
\end{tabular}

Nilai-nilai yang ada dalam hak dan kewajiban di atas juga terdapat lengkap dalam piagam Madinah yang dibuat oleh Nabi Muhammad SAW yang di dalamnya memiliki nilai-nilai universal yang sangat lengkap, yaitu: nilai patriotism, nilai persatuan, nilai toleransi, nilai keadilan, nilai keadilan, nilai kebebasan, nilai persaudaraan, nilai kerjasama, nilai ta'awun, nilai perdamaian, dan nilai kesetaraan. ${ }^{9}$ Dari bermacam-macamnya nilai yang terdapat dalam piagam Madinah tersebut menunjukkan adanya HAM yang sangat dijaga dalam Islam. Miftahul Ulum menyebutkan bahwa di dalam piagam Madinah terdapat tiga jenis hak, yaitu: 1) hak untuk hidup; 2) hak untuk mendapatkan kebebasan, yaitu kebebasan dalam mengeluarkan pendapat, kebebasan beragama, kebebasan

\footnotetext{
${ }^{8}$ Ahmad Kosasih, HAM Dalam Perpektif Islam: Menyingkap Persamaan Dan Perbedaan Antara Islam Dan Barat (Jakarta: Salemba DIniyah, 2003), 40.

9 Majidatun Ahmala and Ahmad Fauzi, "Piagam Madinah Sebagai Model Restrukturisasi Sistem Pemerintahan Demokrasi Di Indonesia," 2019, 252-53.
} 
dari kemiskinan, dan kebebasan dari rasa takut); 3) hak untuk mencari kebahagiaan. ${ }^{10}$

\section{Hak Asasi Manusia Dalam Al-Kulliyat Al-Khams Perpektif Pemikiran Abdurrahman Wahid}

KH Abdurrahman Wahid (Gus Dur) dikenal sebagai pelopor dalam mengintrodusir konsep Islam kultural di Indonesia. Menurut konsep ini,masyarakat muslim harus mampu mengakrabi budaya sekitarnya, karena prinsip universal dalam ajaran Islam mengharuskan mereka mengakomodir budaya partikular yang hidup di tempat tinggal mereka. Pandangan ini dimaksudkan agar kehadiran Islam bisa membawa serta keramahan kepada lingkungannya. Gus Dur nampaknya mengadopsi pendekatan kultural para muballigh awal (wali) Islam. Seperti diketahui bahwa para muballigh tersebut menanggalkan perangkat simbol eksklusif Islam (Arab) dan menggantinya dengan perangkat simbol lokal. Mereka mengintegrasikan ajaran Islam ke dalam simbol lokal agar Islam dapat bersinergi dengan kultur Indonesia. Dengan akulturasi seperti itu, maka transformasi ajaran Islam ke dalam pikiran masyarakat Indonesia bisa berjalan dengan sangat efektif.. ${ }^{11}$ Romo Magniz mengatakan bahwa Gus Dur memproyeksikan gambar positif tentang Islam karena Gus Dur mewujudkan Islam yang percaya diri, positif, terbuka, dan ramah. ${ }^{12}$

Selain itu, Gus Dur juga terkenal dengan sikapnya yang konsisten dalam memperjuangkan nilai-nilai kemanusiaan. Perjuangan akan nilai-nilai kemanusiaan itu terlihat sebagaimana ia memerhatikan nasib kalangan kecil yang tertindas, termasuk kalangan minoritas. ${ }^{13}$ Wahyu Fatah mengatakan bahwa Gus Dur menemukan universalisme Islam dalam ajaran kemanusiaan, yang artinya segenap nilai utama yang meliputi tauhid, fiqh, dan akhlak ternyata menunjukkan

\footnotetext{
${ }^{10}$ Miftahul Ulum, "Fikih Hak Asasi Manusia (Analisis Piaham PBB Dalam Perpektif Hukum Pidana Islam)," Syaikhuna: Jurnal Pendidikan Dan Pranata Islam 8, no. 2 (2017): 163-64, https://doi.org/10.21143/jhp.vol19.no6.1180.

11 Thoha Hanim, Islam NU: Di Bawah Tekanan Problematika Kontemporer (Surabaya: Diantama, 2004$), 63$.

12 Ali Masykur Musa, Pemikiran Dan Sikap Politik Gus Dur (PT Gelora Aksara, 2010), 122-23.

${ }^{13}$ Muhammad Rifa'i, Gud Dur: Biografi Singkat 1940-2009 (Yogyakarta: Garasi, 2014), 12.
} 
kepedulian mendalam atas kemanusiaan. ${ }^{14}$ Menurut Gus Dur Hak Asasi Manusia merupakan salah satu manifestasi dari nilai kemanusiaan. ${ }^{15}$

Gus Dur adalah sosok yang selalu dikenal dengan sikapnya yang selalu menjunjung tinggi demokrasi dan hak-hak asasi manusia, khususnya dalam bidang HAM. boleh dikatakan Gus Dur sebagai pahlawan HAM. Dibukanya paradigma baru oleh Gus Dur dengan menerobos tembok-tembok pemikiran lama. Dia ingin setiap orang mendapat perlakuan yang sama dalam hukum, tanpa membedabedakan warna kulit, etnis, agama, atau ideologinya. Gus Dur menghargai mereka sebagai sesama manusia dan warga negara. ${ }^{16}$

HAM dalam Islam bersifat theosentris karena bentuk larangan dan perintah didasarkan atas sumber ajaran Islam, yaitu Al-Qur'an dan Hadits. Al-Qur'an menjadi transformasi dari kualitas kesadaran manusia. Manusia disuruh untuk hidup dan bekerja di atas dunia ini dengan kesadaran penuh bahwa ia harus menunjukkan kepatuhannya kepada kehendak Allah. Mengakui hak-hak dari manusia adalah sebuah kewajiban dalam rangka kepatuhan kepada-Nya. ${ }^{17}$

Dari penjabaran di atas bukanlah maknanya bahwa dalam Islam manusia tidak mempunyai hak-hak asasi karena dalam Islam manusia hanya mempunyai kewajiban-kewajiban yang harus dilakukan pada Allah dengan mematuhi hukumhukumnya. Secara paradoks, dalam menjalankan kewajiban-kewajiban inilah terdapat semua hak dan kemerdekaannya, bahkan dalam ajaran Islam manusia mengakui hak-hak dari manusia lain merupakan sebuah kewajiban yang dibebankan oleh hukum agama untuk mematuhi Allah. Oleh karena itu, HAM dalam Islam tidak semata-mata menekankan kepada hak asasi manusia saja, akan tetapi hak-hak itu dilandasi kewajiban asasi manusia untuk mengabdi kepada Allah sebagai penciptanya. ${ }^{18}$

\footnotetext{
14 Wahyu Fatah, "Humanisme Gus Dur: Pergumulan Islam Dan Kemanusiaan Sebagai Jawaban Dehumanisasi Di Era Disrupsi," Al-Hikmah: Jurnal Dakwah 14, no. 1 (2020): 105.

15 Puput Dwi Lestari, "Pemikiran Abdurrahman Wahid Tentang Islam Dan Humanisme," MATAN: Journal of Islam and Muslim Society 2, no. 1 (2020): 66, https://doi.org/https://doi.org/10.20884/1.matan.2020.2.1.2272.

${ }^{16}$ Hendri F.Isnaeni, Pahlawan Nasional Bukan Untuk Gud Dur (Jakarta Timur: Mas Media Alam Semesta, 2010), 80.

${ }^{17}$ Wahyu M.S, Ilmu Sosial Dasar (Surabaya: Usaha Nasional, 1986), 106.

${ }^{18}$ M. Abduh Malik, Pengembangan Kepribadian Pendidikan Agama Islam Pada Perguruan Tinggi (Jakarta: Departemen Agama Direktorat Jenderal Pendidikan Islam Direktorak Pendidikan Tinggi Islam, 2009), 64.
} 
Islam adalah agama samawi terakhir yang dengan sempurna menampilkan nilai-nilai kemanusiaan di dalam Islam (Universalisme Islam) yaitu lima buah jaminan dasar (kulliyat al-khams) untuk diberikan kepada warga masyarakat baik secara kelompok maupun individu. Lima jaminan dasar tersebut (1) keselamatan fisik warga masyarakat dari tindakan badani (hifdzun al-nafs); (2) keselamatan keyakinan agama masing-masing, tanpa ada paksaan untuk berpindah agama (hifdzu al-din); (3) keselamatan keluarga dan keturunan ( hifdzun an-nasl); (4) keselamatan harta benda dan milik pribadi dari gangguan atau penggusuran di luar prosedur hukum (hifdzun al-maal); (5) keselamatan hak milik dan profesi ( hifdzun al-aqli). ${ }^{19}$

Kelima hak dasar manusia dalam Islam ini bersumber dari istilah maqashid syari'ah yang prinsinya terbagi dalam tiga macam inti pokok, yaitu: pertama, maqashid al-dharuriyat, yaitu maqashid untuk memelihara lima unsur pokok dalam kehidupan manusia yang meliputi memelihara agama, jiwa, keturunan, akal, dan harta; kedua maqashid al-hajjiyat, yaitu maqashid untuk menghilangkan kesulitan atau menjadikan pemeliharaan terhadap lima unsur pokok menjadi lebih baik lagi; ketiga maqashid al-tahsiniyah yaitu maqashid yang dimaksudkan agar manusia melakukan yang terbaik untuk menyempurnakan pemeliharaan lima unsur pokok. Dengan tidak tercapainya aspek dharuriyat maka akan merusak dunia dan akhirat secara keseluruhan walaupun aspek hajjiyah dan tahsiniyah tidak berhasil tercapai. $^{20}$

Gus Dur senantiasa berpegang pada lima prinsip kemanusiaan (Al-Kulliyat al-Khams) dasar yang selalu ia pegang dalam melindungi dan menjaga hak-hak kemanusiaan. Lima prinsip tersebut adalah hifzh al-din (perlindungan terhadap agama), hifzh al-nafs (perlindungan terhadap jiwa), hifzh al-aql (perlindungan terhadap akal), hifzh al-nasl (perlindungan terhadap keturunan), hifz al-maal (perlindungan terhadap harta). ${ }^{21}$

\footnotetext{
${ }^{19}$ Abdurrahman Wahid, Islam Kosmopolitan Nilai-Nilai Indonesia Dan Transformasi Kebudayaan (Jakarta: The Wahid Institute Seding Plural and Peaceful Islam, 2007), 4-5.

${ }^{20}$ Abdul Manan, Reformasi Hukum Islam Di Indonesia (Jakarta: PT Raja Grafindo, 2006), 108-9.

${ }^{21}$ Ali Imran Nurhayati, Sinaga, Fiqih Dan Ushul Fiqih (Jakarta: Prenamedia Group, 2018), 76.
} 
Pemikiran Gus Dur terhadap kelima nilai kemanusiaan (Al-Kulliyat AlKhams) tersebut atau yang disebut juga sebagai lima hak dasar manusia adalah sebagai berikut:

\section{a. hifzh al-din (perlindungan terhadap agama).}

Gus Dur menyimpulkan bahwa Islam yang dipikirkan dan dialaminya adalah Islam yang khas, yang diistilahkan dengan "Islamku" atau "Islamnya Gus Dur" yang perlu dilihat sebagai rentetan pengalaman pribadi yang perlu diketahui orang lain, tetapi tidak dapat dipaksakan kepada orang lain. Sementara yang dimaksud dengan "Islam Anda" lebih merupakan apresiasi dan refleksi Gus Dur terhadap tradisionalisme atau ritual kepahamaan yang hidup dalam masyarakat. Dalam konteks ini, Gus Dur memberikan apresiasi terhadap kepercayaan dan tradisi keagamaan sebagai "kebenaran" yang dianut oleh komunitas masyarakat tertentu yang harus dihargai. Menurutnya "kebenaran" semacam itu berangkat dari keyakinan, dan bukan dari pengalaman. Keberagaman semacam itu diformulasikan olehnya sebagai "Islam Anda". Adapun perumusan "Islam Kita" merupakan derivasi dari keprihatinan seseorang terhadap masa depan Islam didasarkan pada kepentingan bersama kaum muslimin. Persoalan mendasar dalam konteks "Islam Kita" terletak pada adanya kecenderungan sementara kelompok orang untuk memaksakan "Islam Kita" menurut tafsiran mereka sendiri. dengan kata lain, mereka ingin memaksakan kebenaran Islam menurut tafsirannya sendiri. monopoli tafsir kebenaran Islam seperti ini, menurut Gus Dur bertentangan dengan semangat demokrasi. ${ }^{22}$

Pandangan Islamnya seseorang menurut Gus Dur terbentuk dari pengembaraannya sendiri, baik itu dari pendidikannya, bacaannya, temantemannya, pengalamannya, dan lain sebagainya, dan yang terpenting adalah seseorang tidak dapat memaksakan apa yang ada dalam pandangannya kepada orang lain karena orang lain pun memiliki pengalaman yang berbeda-beda. Hak untuk mendapatkan perlindungan agama merupakan hak setiap individu yang tidak dapat dipaksakan pada orang lain.

Tulisan Gus Dur yang termuat dalam majalah Ilmu sosial tahun 1970-an hingga 180-an, Prisma, mengatakan bahwa jalinan yang sangat kuat antara

\footnotetext{
${ }^{22}$ M. Syafi'i Anwar, ed., Abdurrahman Wahid: Islamku, Islam Anda, Islam Kita (jakarta: Democrazy project Yayasan Abad Demokrasi, 2011), XV-XVI.
} 
aspirasi keagamaan dan aspirasi yang secara nominal terletak di luar lingkup keagamaan (seperti penegakan keadilan, pertumbuhan demokrasi, penjagaan kelestarian alam, dan pengembangan struktur ekonomi yang berwatak kerakyatan). Ajaran-ajaran agama justru dijadikan sumber inspirasional bagi aspirasi "non-keagamaan" tersebut di kalangan gerakan-gerakan keagamaan yang menyajikan alternative bagi sistem pemerintahan yang monolitis. ${ }^{23} \mathrm{Hal}$ ini menunjukkan bahwa ajaran Islam menurut Gus dur memegang peranan penting dalam menggerakkan pemerintahan.

Oleh sebab itu, Gus Dur memberikan perhatian pada dua organisasi kemasyarakatan terbesar di Indonesia yang pada dasarnya memiliki tujuan yang sama, dalam tulisannya yang berjudul "Muhammadiyah-NU: Perbedaankah atau Perpecahan" Gus Dur mengatakan bahwa sikap fanatic dari orang-orang NU maupun orang-orang Muhammadiyah yang nampak hanyalah sis pertentangan dan perpecahannya saja, hal ini disebabkan adanya tekanan pada kelembagaan untuk harus mempertahankan kepentingan/interest kedua perkumpulan tersebut. Pihak sendiri 'dimenangkan' dan pihak lain'dikalahkan', hal inilah yang membuat mereka seolah-oleh saling berhadapan, padahal dalam kenyataannya mereka menganut corak kehidupan yang sama, yaitu mementingkan akhlak/moraltas/etika. ${ }^{24}$

Cara pandangnya pada dua organisasi kemasyarakatan dengan mengatakan bahwa keduanya memiliki corak hidup yang sama menunjukkan bahwasannya Gus Dur tidak melihat perbedaan yang berarti pada kedua organisasi kemasyarakatan yang sering dianggap bersebrangan oleh masyarakat. Hal ini menunjukkan bahwa umat Islam di Indonesia seharusnya saling menjaga demi tercapainya tujuan utama yaitu membentuk akhlak Islami pada setiap pribadi umat Islam sebagaimana yang telah dicontohkan oeh Rasulullah SAW.

\section{b. hifzh al-nafs (perlindungan terhadap jiwa)}

Hermawati mengatakan bahwa Gus Dur mempunyai tiga prinsip dalam hidupnya yaitu: 1) Gus Dur kan selalu berpihak pada yang lemah; 2) antidiskriminasi dalam bentuk apa pun; 3) tidak pernah membenci orang sekalipun

\footnotetext{
${ }^{23}$ Muh Shaleh Isre, ed., Prisma Pemikiran Gus Dur K.H. Abdurrahman Wahid (Yogyakarta: LKiS Yogyakarta, 1999), 54.

${ }^{24}$ M. Imam Aziz, ed., Kumpulan Kolom Dan Artikel Abdurrahman Wahid Selama Era Lengser (Yogyakarta: LKiS Yogyakarta, 2002), 141.
} 
disakiti. $^{25}$ Ketiga hal ini menunjukkan besarnya pendirian Gus Dur akan perlindungan jiwa manusia, baik itu pada yang lemah, teraniaya, maupun pada orang yang teraniaya. Gus Dur seakan mengatakan bahwa setiap jiwa manusia mempunyai hak yang sama di muka bumi ini, sebagaimana dalam Al-Qur'an surat Al-hujurat ayat 13 yang berbunyi: "Wahai Manusia Sungguh, Kami telah menciptakan kamu dari seorang laki-laki dan seorang perempuan, kemudian Kami jadikan kamu berbangsa-bangsa dan bersuku-suku agar kamu saling mengenal. Sesungguhnya yang paling mulia di antara kamu di sisi Allah ialah orang yang paling bertakwa. Sungguh, Allah Maha Mengetahui, Maha Teliti” . Ayat ini pun menjelaskan bahwa di manapun manusia berada mempunyai hak yang sama, karena yang membedakan mereka semua di hadapan Allah SWT adalah ketakwaannya.

Dalam artikelnya yang berjudul "Sistem Budaya Daerah Kita dan Modernisasi' Gus Dur mengambil ungkapan Clifford Geertz dari Universitas Princeton yang menganggap bahwa Kiai/Ulama pesantren sebagai 'makelar budaya' (cultural broker), karena ia melihat bahwa para kiai melakukan fungsi screening bagi budaya Indonesia. Nilai-nilai baru yang dianggap merugikan disaring oleh mereka sehingga masyarakat dilindungi dari pengaruh-pengaruh negatif, dan dibiarkan mengambil pengaruh-pengaruh luar yang positif ${ }^{26}$ Dari tulisan Gus Dur ini menunjukkan bahwa menurutnya, salah satu sebab terjaganya jiwa orang Islam di Indonesia dari pengaruh budaya luar yang tidak sesuai dengan budaya ketimuran dan Islam adalah Kiai/Ulama, hal ini disebabkan para Kiai/Ulama di Indonesia yang menurutnya menjadi penyaring budaya, menjadi panutan dan contoh yang akan diikuti dalam keseharian.

\section{c. hifzh al-aql (perlindungan terhadap akal)}

Kacung Marijan dalam tulisannya yang berjudul 'Gus Dur, dari NU ke Presiden" menulliskan bahwa "Kiai Abdurrahman Wahid (Gus Dur) adalah seorang intelektual yang cerdas, bahkan luar biasa (an outstanding intellectual). Kesan ini muncul karena Gus Dur rajin memproduksi atau mereproduksi gagasangagasan genuine melalui tulisan-tulisan dan serpihan-serpihan lontaran. Cara

\footnotetext{
25 Maswan dan Aida Farichatul Laila, Pendapat Tokoh Tentang Gus Dur: Manusia Multidimensional (Yogyakarta: Deepublish, 2015), 125.

${ }^{26}$ Aziz, Kumpulan Kolom Dan Artikel Abdurrahman Wahid Selama Era Lengser, 162.
} 
menyampaikan gagasannya dilakukan secara sederhana sehingga relatif mudah dipahami. Apalagi Gus Dur bisa berkomunikasi dengan berbagai lapisan masyarakat secara mudah, baik kelas bawah, mayoritas NU, maupun kelas menengah ke atas. Kemampuan ini tidak dimiliki oleh semua intelektual, termasuk semua kiai di lingkungan NU. ${ }^{27}$

Kecerdasannya ini dituangkan dalam tulisan-tulisannya yang tersebar di berbagai media. Salah satu artikelnya yang berjudul "membaca sejarah lama" di Poso, 4 Maret 2002, Gus Dur menceritakan bahwa ia harus berjalan kaki tiga setengah kilometer untuk mencapai makam Syaikh Abdullah Qutbuddin, pembawa tarekat Qodariyah pertama kali di pulau Jawa. Hal ini dilakukan karena kelangkaan sumber tertulis tentang runtuhnya kerajaan kalingga yang beragama Hindu di pegunungan Dieng. Karena Gus Dur menganggap sirnanya kerajaan Kalingga disebabkan munculnya budaya campuran Hindu-Budha di Jawa Tengah dan datangnya Islam dalam bentuk Tarekat Qodariyah. ${ }^{28}$ Hal ini menunjukkan perhatiannya yang besar akan dunia intelektual yang harus dilestarikan dalam bentuk tulisan agar sejarah emas bangsa Indonesia dapat diketahui dengan pasti. Selain itu, banyaknya tulisan-tulisan yang dihasilkannya merupakan perwujudan dari perhatiannya yang sangat besar akan dunia intelektual.

Menurutnya, dalam Islam ada dua macam pengetahuan, yaitu sekedar tahu (to know) saja, atau pengertian (understanding), yang awal dinamai ma'rif dan yang kedua dinamai ilm (pelakunya disebut 'arif dan alim). Betapa banyak hal-hal tragis/menyedihkan terjadi karena manusia tidak dapat membedakan antara mengetahui dan mengerti akan perjalanan hidup. ${ }^{29}$ maka, dalam hal ini menurutnya, memahami sebuah ilmu pengetahuan tidaklah cukup hanya dengan sekedar tahu tetapi juga harus benar-benar mengerti tentang esensi dari sebuah ilmu pengetahuan dengan menggalinya lebih dalam.

\section{d. hifzh al-nasl (perlindungan terhadap keturunan)}

Dalam sebuah sesi wawancara, ketika Gus Dur ditanya tentang cita-cita apa yang ingin ditanamkan oleh seorang Gus Dur pada anak-anaknya, ia mengatakan bahwa semuanya ia serahkan pada keinginan anak-anaknya. Salah satu alasan

\footnotetext{
${ }^{27}$ Ahmad Suaedy dan Ulil Absar Abdalla, ed., Gila Gud Dur: Wacana Pembaca Abdurrahman Wahid (Yo: LKiS, 2000), 129.

${ }^{28}$ Aziz, Kumpulan Kolom Dan Artikel Abdurrahman Wahid Selama Era Lengser, 97-98.

${ }^{29}$ Alvian Muhammad dan Helmi Jacob, Gus Dur Bertutur (Jakarta: Harian Proaksi dan Gud Dur Foundation, 2005), 73.
} 
yang membuatnya tidak memaksakan cita-citanya kepada anak-anaknya adalah karena anak-anaknya perempuan semua. Menurutnya, ketika anak-anaknya tersebut menikah, mereka harus menyesuaikan dengan kehidupan suaminya. Gus Dur menanamkan tanggung jawab pada anak-anaknya dan tidak terlalu menuntut anaknya untuk berprestasi karena takut bahwa tuntutan berprestasi akan mendera mereka, karena menurutnya ia dulu juga bukanlah anak yang berprestasi. ${ }^{30}$

,Dari wawancara tersebut menunjukkan bahwa seorang Gus Dur memberikan kebebasan pada anak-anaknya untuk menentukan pilihannya sendiri, namun kebebasan yang diberikan pada anak-anaknya itu disertai dengan rasa tanggung jawab atas segala keputusan dan bukan bebas tanpa batas. Di sisi lain, di antara kemajuan perkembangan zaman dan gencarnya arus tuntutan gender, seorang Gus Dur justru berpandangan bahwa seorang perempuan merupakan tanggung jawab suami. Sebagaimana ajaran Islam, di mana seorang anak perempuan yang telah menikah merupakan tanggung jawab suaminya dan ketaatannya pun diberikan pada suaminya. Hal ini menunjukkan bahwa Gus Dur memahami benar akan hak dan kewajiban seorang anak perempuan pada khususnya.

\section{e. hifz al-maal (perlindungan terhadap harta).}

Menurut Gus Dur, gagasan ekonomi Islam terlalu memfokuskan pada aspek-aspek normatif, dan kurang mempedulikan aplikasinya dalam praktek yang justru diperlukan bagi masyarakat. Oleh sebab itu, Gus Dur tanpa ragu mendukung "ekonomi kerakyatan" yang didasarkan atas pertimbangan. Pertama, dalam konsepsi Islam, orientasi ekonomi haruslah memperjuangkan nasib rakyat kecil serta kesejahteraan rakyat banyak, yang dalam teori ushul fiqh dinamakan al-maslahah al-ammah. Kedua, mekanisme yang digunakan untuk mencapai kesejahteraan itu tidaklah ditentukan format dan bentuknya. Oleh karena itu, acuan dan praktek perdagangan bebas dan efisiensi yang dibawakan oleh sistem kapitalisme tidaklah bertentangan dengan Islam karena Islam sendiri mengajarkan fastabiqul khairat (berlomba dalam kebaikan). Bahkan dalam persaingan dan perlombaan yang sehat, akan dihasilkan kreatifitas dan efisiensi yang justru menjadi inti dari praktek ekonomi yang sehat pula. Dalam bahasa Gus Dur "Umat Islam bisa menerima pelaksanaan prinsip-prinsip Islam dalam orientasi

\footnotetext{
${ }^{30}$ M. Saleh Isre, ed., Tabayun Gus Dur: Pribumisasi Islam Hak Minoritas Reformasi Kultural, Yogyakarta (LKiS, 1998), 198.
} 
kapitalistik tanpa harus memeluk kapitalisme itu sendiri." yang ditentang oleh Islam adalah orientasi kapitalistik yang hanya mengutamakan pengusaha besar dan pemilik modal, sebab dalam Islam yang terpenting justru kesejahteraan rakyat secara keseluruhan. ${ }^{31}$

Dalam artikelnya yang berjudul "Mencintai yang kecil bukan mencintai yang besar" Gus Dur mengatakan bahwa Usaha untuk mendorong ekonomi rakyat dilakukan melalui Usaha Kecil Menengah (UKM), melalui tiga hal, yaitu: 1) Pemberian kredit murah yang berbunga sangat rendah kepada UKM. Hal ini menurutnya dapat membesarkan UKM dengan cepat dan menciptakan lapangan pekerjaan lebih banyak, serta kemudahan dalam memperoleh penghasilan tambahan yang jauh lebih besar dari yang diperoleh sekarang. 2) Pengorganisasian yang lebih baik. Yang artinya penciptaan pasaran baru bagi pilihan teknologi yang tepat terhadap produksi mereka, pembuatan kemasan yang lebih menarik perhatian dan pencernan informasi baru yang lebih daripada yangdidapat ini. Dengan kombinasi ini, UKM akan dapat bersaing dan bergerak secepat usaha-usaha besar dan raksasa. 3) Dengan merintis kebijakan-kebijakan baru yang selama ini hanya menguntungkan perusahaan besar dan raksaasa. ${ }^{32}$

Penjabaran di atas menunjukkan bahwa Gus Dur menghendaki sebuah sistem perekonomian yang berpihak pada rakyat dan memberi implikasi langsung pada rakyat dan bukan hanya pada sebagian penguasa dan pengusaha sebagaimana ajaran Islam. Mengembalikan perekonomian yang berpihak pada rakyat adalah harapan seorang Gus Dur dalam mewujudkan kesejahteraan secara keseluruhan. Maka, kesejahteraan ekonomi rakyat merupakan hak yang harus diberikan sebagaimana ajaran Islam.

Hidup Gus Dur jika direnungkan lebih dalam, memang merupakan jembatan yang mencoba menghubungkan banyak orang agar bisa menjamin komunikai setara, setiap bentuk perbedaan, termasuk perbedaan keyakinan dan menjadi masalah. Gus Dur selalu berangkat dari ajaran Islam yang damai dan universal yang menempatkan manusia pertama-tama sebagai ciptaan Tuhan.

\footnotetext{
${ }^{31}$ Anwar, Abdurrahman Wahid: Islamku, Islam Anda, Islam Kita, xxix.

32 Dewi Fortuna Anwar, Gus Dur Versus Militer: Studi Tentang Hubungan Sipil-Militer Di Era Transisi Jakarta (jakarta: Grasindo, 2002), 154.
} 
Sebab manusia adalah ciptaan Tuhan, tidak ada pengotak-kotakan manusia yang putih, kuning, coklat, dan hitam. ${ }^{33}$

Lima prinsip kemanusiaan dasar tersebut adalah hifzh al-din (perlindungan terhadap agama), hifzh al-nafs (perlindungan terhadap jiwa), hifzh al-aql (perlindungan terhadap akal), hifzh al-nasl (perlindungan terhadap keturunan), hifz al-maal (perlindungan terhadap harta). ${ }^{34}$ Semua itu dilakukan Gus Dur karena ia menganggap bahwa manusia dan kemanusiaan adalah fokus pikiran dan perhatian utama nya, berhari-hari, siang, dan malam dan pada setiap napas yang berhembus. Ia Mencintai manusia, dan oleh sebab itu ia bekerja keras menerjemahkan prinsip-prinsup kemanusiaan yang menjadi hak-hak dasarnya. ${ }^{35}$

Melalui pendapat-pendapat Gus Dur yang genuine, mendasar, dan konstektual sebagaimana contoh yang di atas, tampak sekali bagaimana ia, dan komitmennya dalam memperjuangkan terwujudnya penghargaan dan penghormatan atas hak-hak kemanusiaan. Karena bagi Gus Dur prinsip-prinsip kemanusiaan universal atau hak-hak kemanusiaan tersebut sejalan dengan visi agama-agama, terutama agama Islam. ${ }^{36}$

\section{Kesimpulan}

Abdurrahman Wahid atau yang akarab dipanggil dengan Gus Dur telah mengajarkan banyak hal tentang makna kemanusiaan yang sesungguhnya. Kelima prinsip kemanusiaan Universal atau yang disebut dengan Al-Kulliyat al-Khams menjadi lima hak dasar yang diperjuangkan Gus Dur dalam kesehariannya. Kelima prinsip yang ia perjuangkan tersebut, yaitu hifzh al-din (perlindungan terhadap agama), hifzh al-nafs (perlindungan terhadap jiwa), hifzh al-aql (perlindungan terhadap akal), hifzh al-nasl (perlindungan terhadap keturunan), hifz al-maal (perlindungan terhadap harta). Lima prinsip tersebut ia ambil dari teori Ushul Fiqh (Dasar-dasar Hukum) yang ditemukannya dalam kitab klasik pesantren. Nama populernya Al-Kulliyat al-Khams (Lima Prinsip Kemanusiaan Universal).

\footnotetext{
${ }^{33}$ F.Isnaeni, Pahlawan Nasional Bukan Untuk Gud Dur, 110.

${ }^{34}$ Nurhayati, Sinaga, Fiqih Dan Ushul Fiqih, 76.

${ }^{35}$ Muhammad, Sang Zahid: Mengarungi Sufisme Gud Dur, 5.

${ }^{36}$ Muhammad, 8.
} 
Menurut Gus Dur hak untuk mendapatkan perlindungan agama merupakan hak setiap individu yang tidak dapat dipaksakan pada orang lain. Menurut Gus dur, setiap jiwa manusia mempunyai hak yang sama dengan yang lain, hal ini terlihat dari perjuangannya dalam membela pihak yang lemah ataupun yang teraniaya. Gagasan-gagasan Gus Dur yang genuine pun tergambar dalam tulisantulisanya dan perhatiannya dalam dunia intelektual yang mudah dipahami oleh berbagai lapisan masyarakat. Hak seorang anak untuk mendapatkan kebebasan diberikan oleh Gus Dur melalui pola pengasuhannya pada anaknya, namun kebebasan tersebut diiringi dengan tanggung jawab dan berpegang pada ajaran Islam. Hak untuk mendapatkan peningkatan ekonomi bagi segenap lapisan masyarakat dilakukan oleh Gus Dur dengan konsep membangun ekonomi kerakyatan yang diwujudkan dalam pengoptimalan Usaha Kecil Menengah.

\section{Daftar Pustaka}

Abdalla, Ahmad Suaedy dan Ulil Absar, ed. Gila Gud Dur: Wacana Pembaca Abdurrahman Wahid. Yo: LKiS, 2000.

Ahmala, Majidatun, and Ahmad Fauzi. "Piagam Madinah Sebagai Model Restrukturisasi Sistem Pemerintahan Demokrasi Di Indonesia,” 2019, 243-60.

Anwar, Dewi Fortuna. Gus Dur Versus Militer: Studi Tentang Hubungan SipilMiliter Di Era Transisi Jakarta. jakarta: Grasindo, 2002.

Anwar, M. Syafi'i, ed. Abdurrahman Wahid: Islamku, Islam Anda, Islam Kita. jakarta: Democrazy project Yayasan Abad Demokrasi, 2011.

Aziz, M. Imam, ed. Kumpulan Kolom Dan Artikel Abdurrahman Wahid Selama Era Lengser. Yogyakarta: LKiS Yogyakarta, 2002.

Deillerd, Andree. Islam et Amee Dans L'Indonesie Contemporaine Les Pionniers de La Tradition. Edited by Terj. Lesmana. Yogyakarta: LKiS, 1999.

F.Isnaeni, Hendri. Pahlawan Nasional Bukan Untuk Gud Dur. Jakarta Timur: Mas Media Alam Semesta, 2010.

Fatah, Wahyu. "Humanisme Gus Dur: Pergumulan Islam Dan Kemanusiaan Sebagai Jawaban Dehumanisasi Di Era Disrupsi." Al-Hikmah: Jurnal Dakwah 14, no. 1 (2020): 95-114. 
Hanim, Thoha. Islam NU: Di Bawah Tekanan Problematika Kontemporer. Surabaya: Diantama, 2004.

Isre, M. Saleh, ed. Tabayun Gus Dur: Pribumisasi Islam Hak Minoritas Reformasi Kultural. Yogyakarta. LKiS, 1998.

Isre, Muh Shaleh, ed. Prisma Pemikiran Gus Dur K.H. Abdurrahman Wahid. Yogyakarta: LKiS Yogyakarta, 1999.

Jacob, Alvian Muhammad dan Helmi. Gus Dur Bertutur. Jakarta: Harian Proaksi dan Gud Dur Foundation, 2005.

Kosasih, Ahmad. HAM Dalam Perpektif Islam: Menyingkap Persamaan Dan Perbedaan Antara Islam Dan Barat. Jakarta: Salemba DIniyah, 2003.

Laila, Maswan dan Aida Farichatul. Pendapat Tokoh Tentang Gus Dur: Manusia Multidimensional. Yogyakarta: Deepublish, 2015.

Lestari, Puput Dwi. "Pemikiran Abdurrahman Wahid Tentang Islam Dan Humanisme." MATAN: Journal of Islam and Muslim Society 2, no. 1 (2020): 57-73. https://doi.org/https://doi.org/10.20884/1.matan.2020.2.1.2272.

M.I.Patwari. Human Rights in Islamic Law. Edited by Tahir Mahmood. New Delhi: Jaia Nagar, 1993.

M.S, Wahyu. Ilmu Sosial Dasar. Surabaya: Usaha Nasional, 1986.

Malik, M. Abduh. Pengembangan Kepribadian Pendidikan Agama Islam Pada Perguruan Tinggi. Jakarta: Departemen Agama Direktorat Jenderal Pendidikan Islam Direktorak Pendidikan Tinggi Islam, 2009.

Manan, Abdul. Reformasi Hukum Islam Di Indonesia. Jakarta: PT Raja Grafindo, 2006.

Muhammad, Husein. Sang Zahid: Mengarungi Sufisme Gud Dur. Yogyakarta: LKiS, 2012.

Muhtaj, Majda El. Hak Asasi Manusia Dalam Konstitusi Indonesia Dari UUD 1945 Sampai Dengan Perubahan UUD 1945 Tahun 2002. Jakarta: Kencana Prenada Media Group, 2005.

Musa, Ali Masykur. Pemikiran Dan Sikap Politik Gus Dur. PT Gelora Aksara, 2010.

Nurhayati, Sinaga, Ali Imran. Fiqih Dan Ushul Fiqih. Jakarta: Prenamedia Group, 2018.

Rifa'i, Muhammad. Gud Dur: Biografi Singkat 1940-2009. Yogyakarta: Garasi, 2014. 
Jurnal Keislaman, Vol. 4, No. 2, September

Ulum, Miftahul. "Fikih Hak Asasi Manusia (Analisis Piaham PBB Dalam Perpektif Hukum Pidana Islam)." Syaikhuna: Jurnal Pendidikan Dan Pranata Islam 8, no. 2 (2017): 519. https://doi.org/10.21143/jhp.vol19.no6.1180.

Wahid, Abdul. Karena Kau Manusia, Sayangi Manusia. Yogyakarta: Diva Press, 2018.

Wahid, Abdurrahman. Islam Kosmopolitan Nilai-Nilai Indonesia Dan Transformasi Kebudayaan. Jakarta: The Wahid Institute Seding Plural and Peaceful Islam, 2007.

Winardi, Sirajuddin dan. Dasar-Dasar Hukum Tata Negara Indonesia. Malang: Setara Press, 2015. 